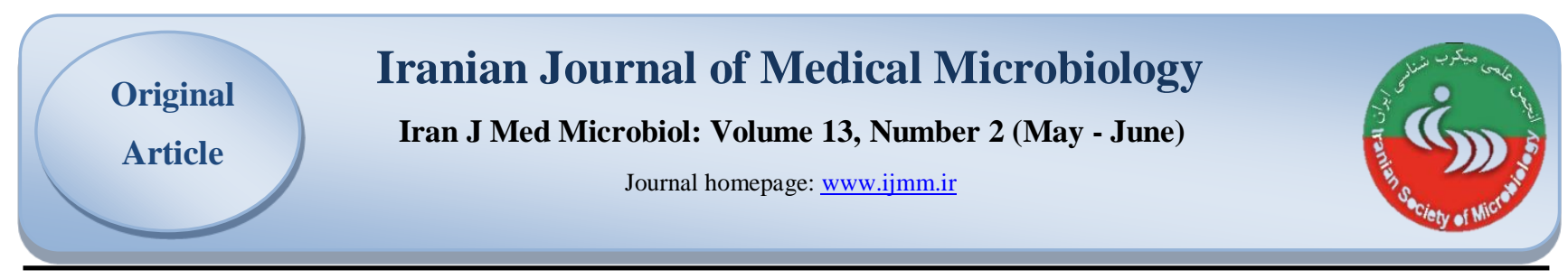

\title{
Molecular Detection of Ureaplasma urealyticum and Chlamydia trachomatis in
} Women with Endometriosis

\author{
Samira Dahaghin ${ }^{1}$, Reza Hosseini Doust ${ }^{1}$, Reza Mirnejad ${ }^{2 *}$
}

1. Department of Microbiology, Faculty of Advanced Science and Technology, Tehran Medical Sciences, Islamic Azad University, Tehran, Iran

2. Molecular Biology Research Center, Systems biology and poisonings institute, Baqiyatallah University of Medical Sciences, Tehran, Iran

\section{Article Information}

\section{Article Subject:}

Molecular Microbiology

DOI:

Corresponding author:

\section{Reza Mirnejad,}

Research Center for Molecular

Biology, Baqiyatallah University of Medical Sciences, Tehran, Iran

Email:

rmirnejad@bmsu.ac.ir

Use your device to scan and read the article online

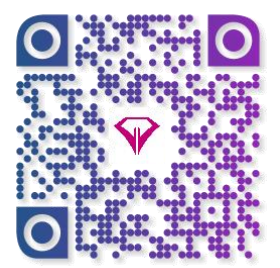

\begin{abstract}
Background and Aims: Endometriosis is considered to be one of the most common women's diseases in the world. The exact cause of endometriosis is unknown. In this study, the bacterial agents were considered as the probable factors influencing this disease and the frequency of two bacteria $U$. urealyticum and C. trachomatis was studied in this disease.

Materials and Methods: This study was performed on Pap smear samples of 50 women with endometriosis, 48 healthy women referred to hospitals in north of Tehran. The recommend samples were transferred to the laboratory, their DNA was extracted, and PCR method was performed. They were analyzed by descriptive statistics.

Results: Performing PCR test for $U$. urealyticum detection among the pap smears of people with endometriosis and non_endometriosis, 27 samples (54\%) and 25 samples (52\%) were positive respectively but none of the samples had contamination with $C$. trachomatis. The highest prevalence of $U$. urealyticum in both endometriosis and healthy subjects was observed in the age group of 30-35 years.

Conclusion: The prevalence of $U$. urealyticum in patients with endometriosis and healthy subjects (non_endometriosis) was relatively similar and the same as normal flora. There was no infection with $C$. trachomatis in these individuals, therefore there was no significant association between these bacteria and endometriosis. For more accurate results such studies should be done in a higher statistical society.
\end{abstract}

Keywords: PCR, U. urealyticum, C. trachomatis, Endometriosis

How to cite this article:

Dahaghin S, Hosseini Doust R, Mirnejad R. Molecular Detection of Ureaplasma urealyticum and Chlamydia trachomatis in Women with Endometriosis. Iran J Med Microbiol. 2019; 13 (2) :125-131 


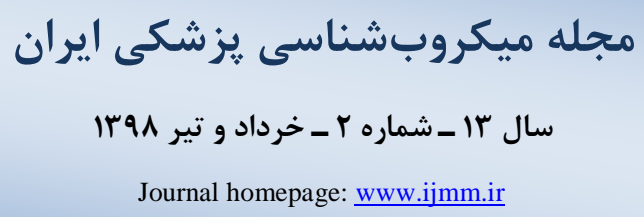

\title{
شناسايى مولكولى Ureaplasma urealyticum و Chlamydia trachomatis
}

\author{
در زنان مبتلا به اندومتريوز

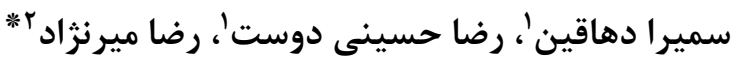

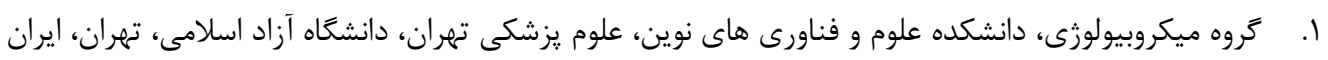

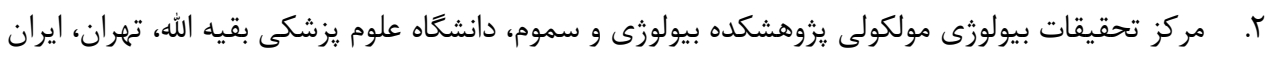

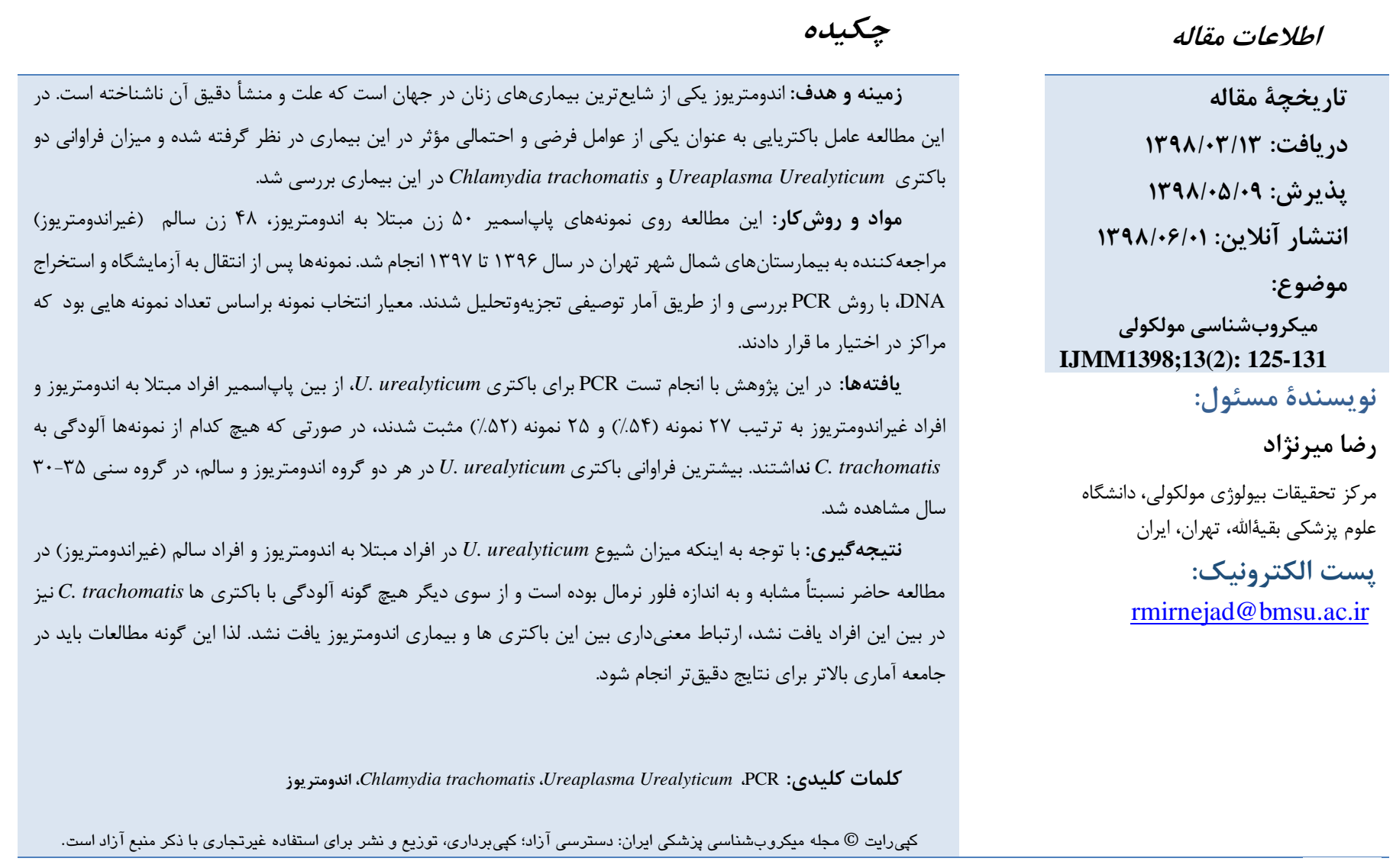

مقدمه

تا • r درصد اعلام شد (r). اندومتريوز به طور قابل ملاحظهاى بر

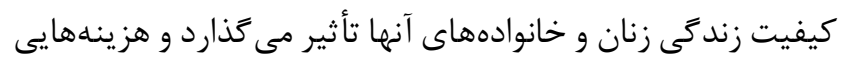
همانند ساير بيمارىهاى مزمن مانند ديابت نوع ؟، بيمارى كرون

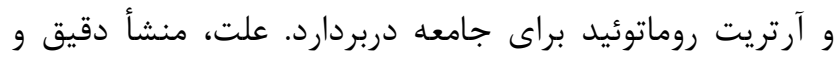
ياتوفيزيولوزى اندومتريوز ناشناخته است، با اين حال ممكن است عوامل زنتيكى و محيطى در آن دخالت داشته باشند (f). در اين

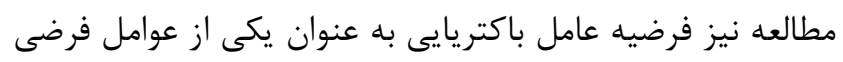

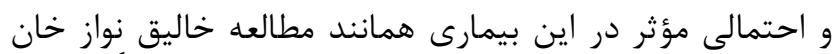

اندومتريوز به حضور و رشد بافت رحم در جايى خارج از حفره رحمى اطلاق مىشود كه يك بيمارى مزمن و ييجٍيده اى

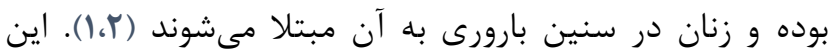
بيمارى با نابارورى و دردهاى مزمن لكنى (در هنگام سيكل قاعدگى و هنگًام مقاربت و هس از آن) ارتباط دارد و به عنوان يكى

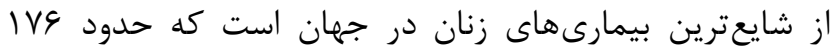
ميليون زن، مبتلا به آن هستند (ب). شيوع تقريبى انـدومتريوز در

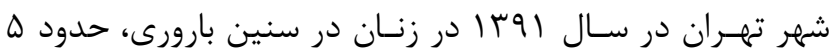


با برسشنامه تهيه شد كه براساس آن، هيج يك از كروههاى مورد

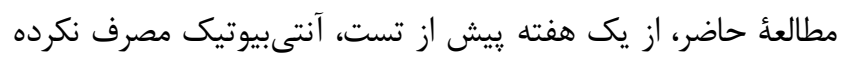

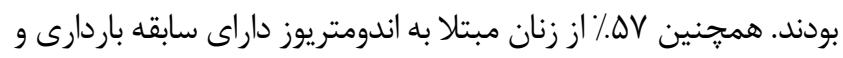

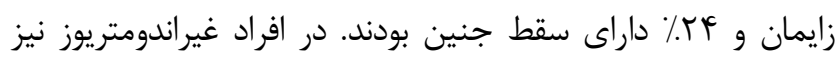

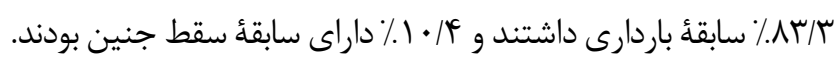

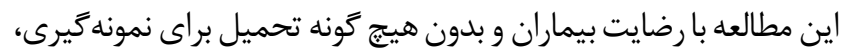

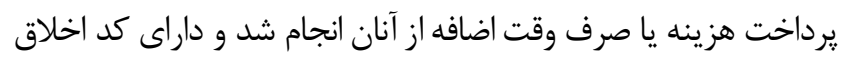

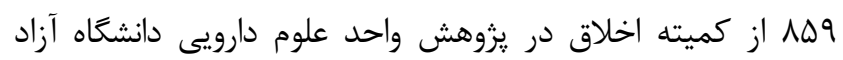

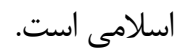

نمونه گيرى سوآب اندوسرويكال توسط متخصص زنان انجام شد

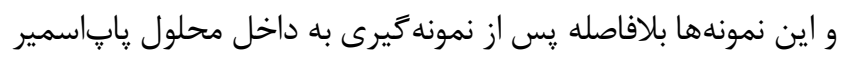

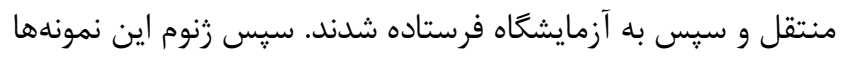

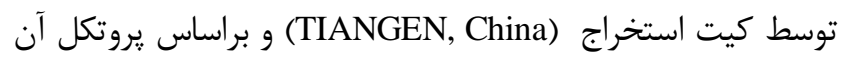

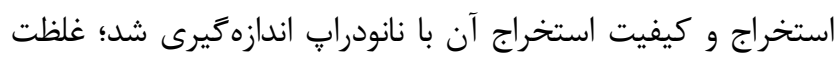

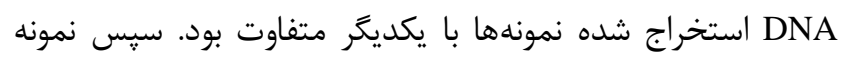

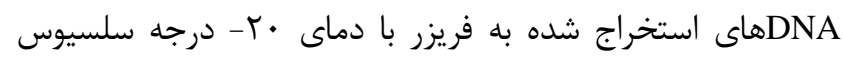

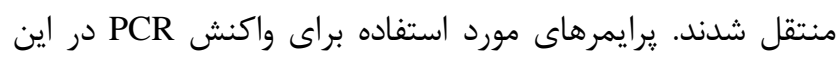

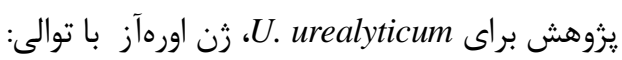

\section{F 5 ` TGG AGT TAA GTC GTA ACA AG-3`}

\section{R 5`CTG AGA TGT TTC ACT TCA CC-3}

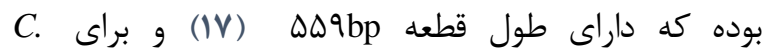
orf8 trachomatis

\section{F:5'-CTAGGCGTTTGTACTCCGTCA-3'}

\section{R:5'-TCCTCAGGAGTTTATGCACT-3'}

و طول قطعه bp • · است (1)). واكنش PCR با حجم نهايى rb ميكروليتر براى هر نمونه انجام شد كه شامل r I ميكروليتر (Ampliqon Co, Skovlunde, Denmark, Cat. No. مسترميكس نماند (180301، 1 ميكروليتر از هر جفت يرايمر، 9 ميكروليتر آب مقطر

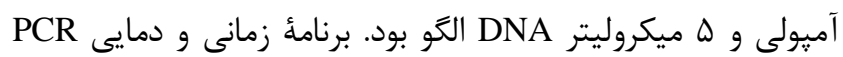

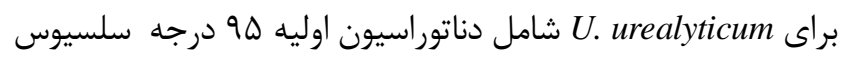

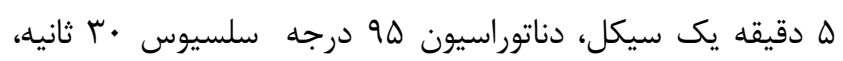

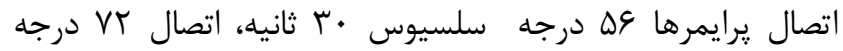

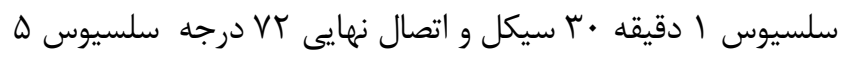

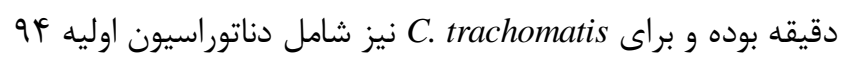

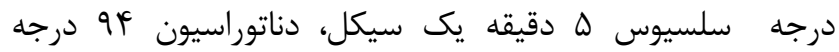

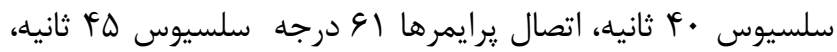

و و همكارانش (هhaleque Newaz Khan) بررسى شد كه آيا ارتباطى بين عفونت با بعضى از عوامل زنيتال مانند Chlamydia trachomatis , Ureaplasma urealyticum بيمارى اندومتريوز وجود دارد يا خير. Urealyticum فاقد U. Uاقد ديواره

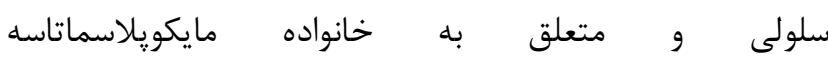
است. اين ميكروار كانيسم به عنوان فلور

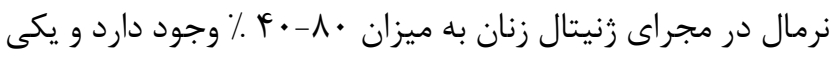

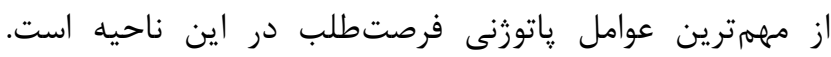
C. trachomatis عنوان يك ياتورن داخل سلولى اجبارى شناخته شده است. اين دو باكترى از شايعترين عوامل منتقل شده از راه جنسى هستند كه إنها

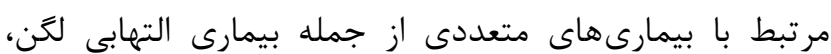

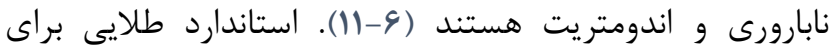
شناسايى اين دو باكترى روش كشت است كه معايبى دارد. از

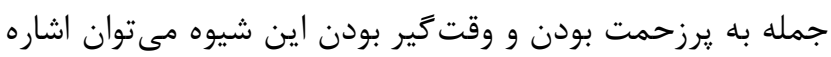

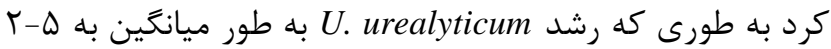
روز زمان نياز داشته و همجنين اين روش نياز به محيطهاى كشت دان

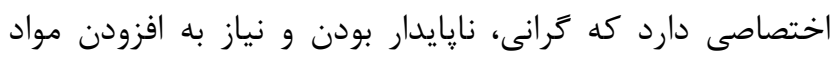
مكمل به اين محيطها از معايب ديخر تكنيك كشت است. كشت إنت C. trachomatis و از سوى ديخر زند كى آن در طول مراحل جمع آورى نمونه، انتقال

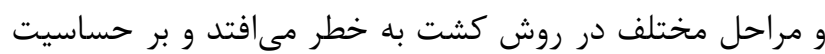

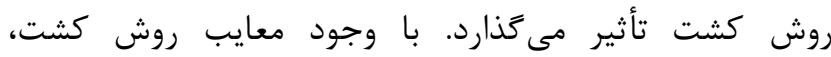

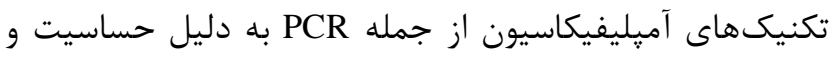

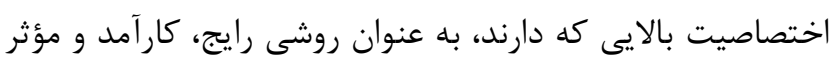

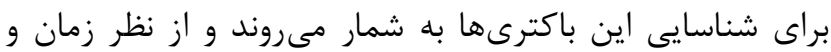
هزينه حتى براى تعداد زياد نمونه نيز مناسبتر هستند (rائ-19).

هدف از اين مطالعه بررسى فراوانى U. urealyticum و C. trachomatis وجود يا عدم وجود ارتباط بين اين باكترىها و اين بيمارى است.

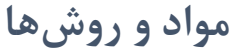

اين يزوهش از خرداد عوسا تا شهريور لوجا روى •ل نمونه

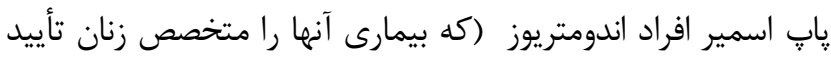

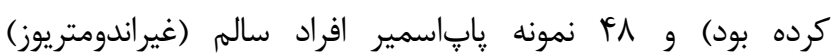
مراجعه كننده به مراكز درمانى شمال شهر تهران كه در محدوده سنى

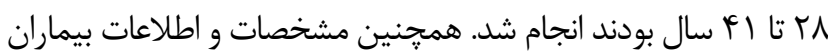
شامل سن، سابقه باردارى، سابقه سقط جنين و مصرف آنتى بيوتيك نيز 


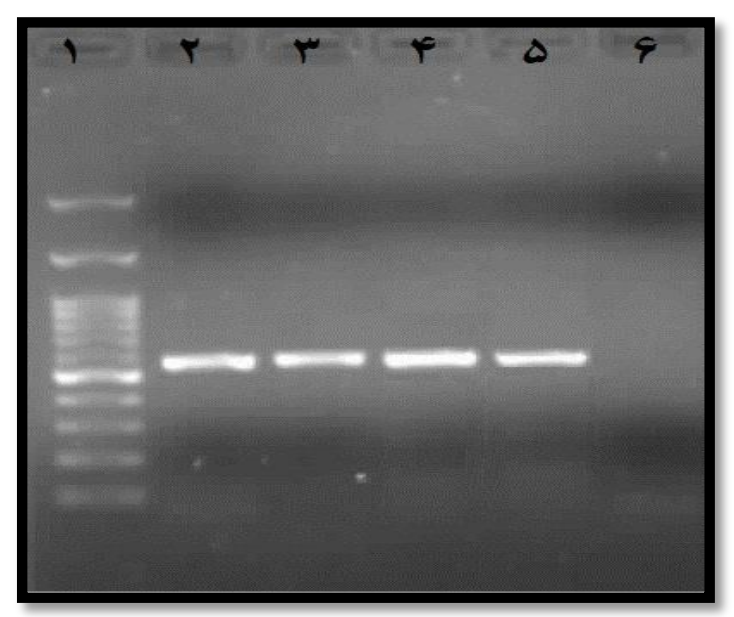

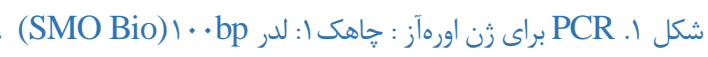

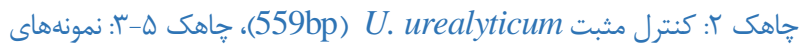

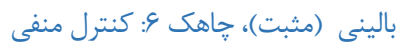

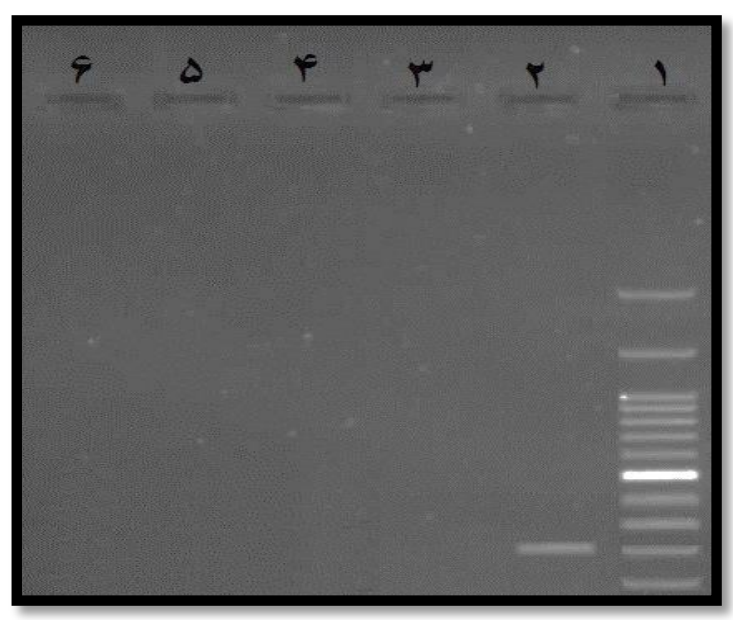

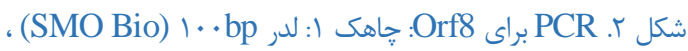

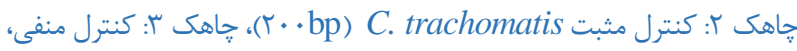

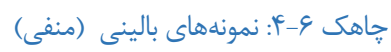

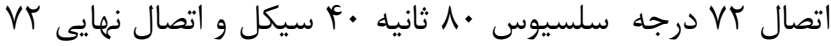
درجه سلسيوس ه دقيقه است.

سيس براى بررسى نتايج PCR، از الكتروفورز روى زل 1٪ استفاده شده و زل الكتروفورز شده توسط دستخاه زل داك مشاهده شد. يس از تأييد باندهاى مورد نظر براى محصولات PCR شده، تعدادى از اين نمونهها جهت تأييد و اطمينان، براى تعيين توالى به شركت بريشعام

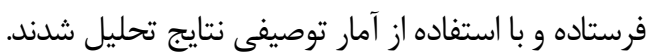

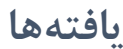

در اين يزوهش بيشترين فراوانى در گروه اندومتريوز، در افراد بالاى هـ سال و بيشترين فراوانى در كروه سالم (غيراندومتريوز) بين هَr-•r سال بود. با انجام تست PCR براى باكترى U. urealyticum،

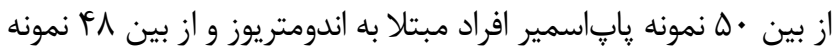

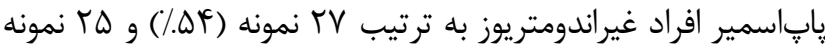

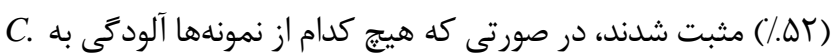
trachomatis

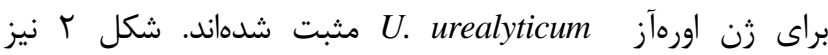
نشاندهنده عدم وجود باند و در نتيجه منفى بودن نمونهها از نظر باكترى C. trachomatis است. توزيع افراد شركت كننده در اين مطالعه ندان براساس گروه هاى سنى و ار كانيسمهاى جدا شده نيز در جدول النشان

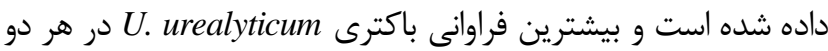

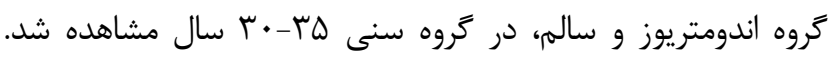
همجنين نتايج تعيين توالى سويههاى كنترل و نمونههاى بالينى به

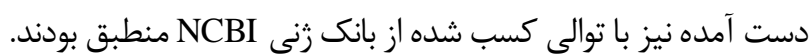

جدول ا ـ توزيع فراوانى باكترىها بر اساس سن

\begin{tabular}{|c|c|c|c|c|c|c|}
\hline \multicolumn{3}{|c|}{ نمونه هاى اندومتريوز } & \multicolumn{3}{|c|}{ نمونههاى سالم (غيراندومتريوز) } & \multirow[b]{2}{*}{ محدوده سنى } \\
\hline تعداد C.t مثبت شده & تعداد U.u مثبت شده & 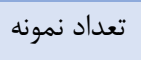 & تعداد C.t مثبت شده & تعداد U.u مثبت شده & 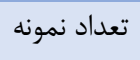 & \\
\hline · & r & $\Delta$ & · & r & $\wedge$ & زير ·r \\
\hline · & 10 & rI & $\cdot$ & If & $r \Delta$ & $r \cdot-r \Delta$ \\
\hline$\cdot$ & $1 \cdot$ & TY & - & $\wedge$ & 10 & 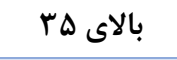 \\
\hline - & TV & $\Delta \cdot$ & - & ra & \&A & جمع كل \\
\hline
\end{tabular}


عفونت وازينال(191 نمونه)، آلودگى با باكترى U. urealyticum

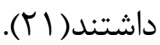
تفاوت در نوع نمونه هاى مطالعه Saigal (ادرار و سواب مجارى ادرارى) و نيز استفاده از بيماران در دو جنس مرد و زن نيز مى تواند

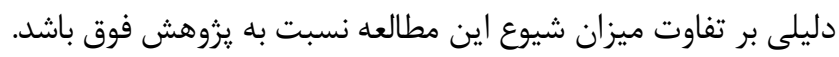
همجنين شيوع پايين تر اين باكترى در مطالعه حسنى نيز مى تواند به علت تفاوت در نوع بيمارى افراد مورد مطالعه آنان باشد.

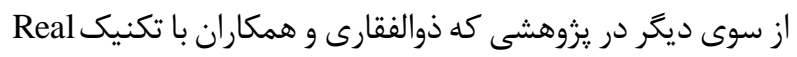
time PCR اندوسرويكال از خانم هاى داراى عفونت وازينال (وازينيت و و

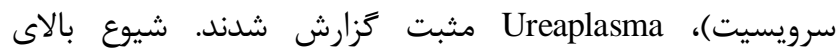
Ureaplasma

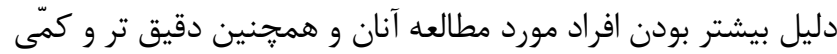

بودن بودن تكنيك Real time PCR نسبت به PCR باشد) • (Y). همجنين عليرغم عدم شيوع C. trachomatis در مطالعه حاضر،

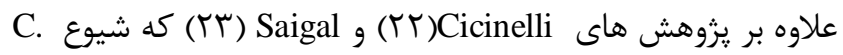
PCR به ترتيب PC trachomatis

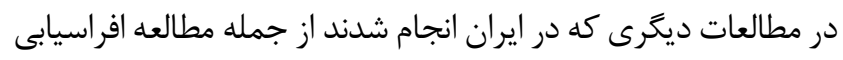

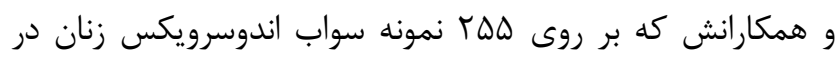

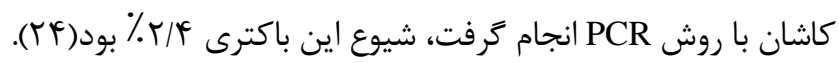

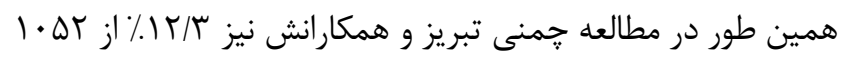

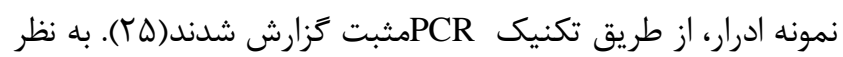
مى رسد دليل عدم وجود اين باكترى در نمونه هاى مطالعه حاضر

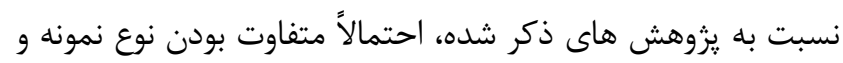

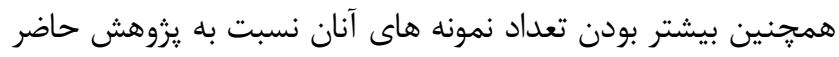

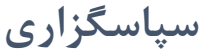

اين يزوهش در مركز تحقيقات بيولوزى مولكولى بقيئالله

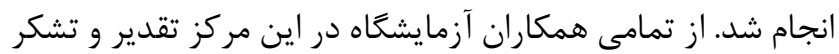
مى كنيه. اين مقاله حاصل بخشى از زايان نامه كارشناسى ارشد سميرا دهاقين تحت عنوان " شناسايى مولكولى لurealyticum و C.trachomatis در زنان مبتلا به بيمارى اندومتريوز

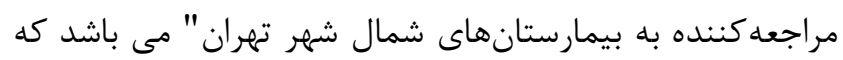

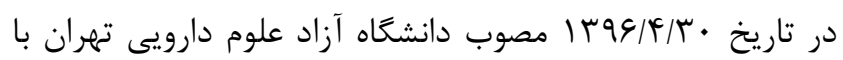

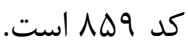

\section{تعارض منافع}

بين نويسندگان تعارض در منافع ززارش نشده است.
در اين يزوهش بيشترين فراوانى U. urealyticum در بين افراد

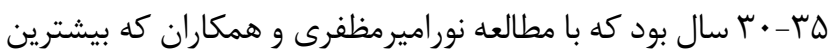

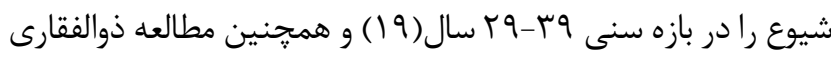

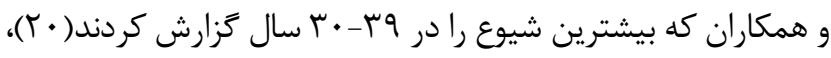

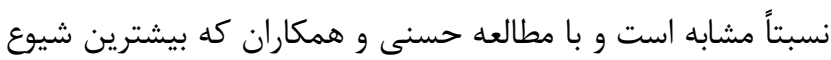

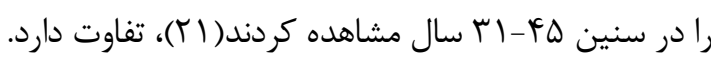
همجنين در مطالعه حاضر از بين افراد مبتلا به اندومتريوز و افراد

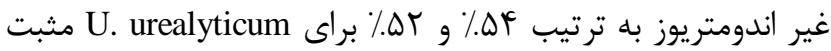

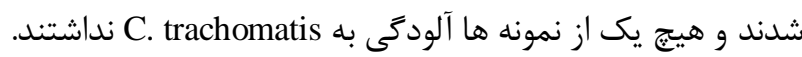
در مطالعه Khaleque Newaz Khan و همكارانش كه مشابه

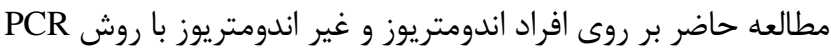

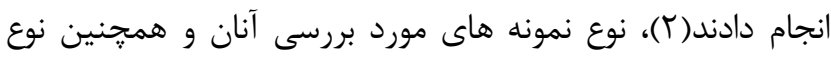
باكترى هايى كه شناسايى كردند (استريتوكوى ها و استافيلوكوى نمان

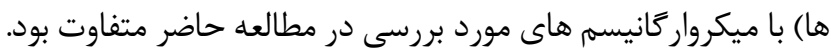

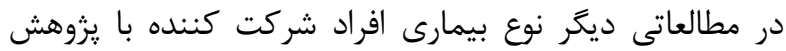

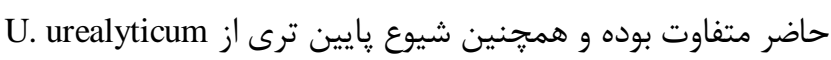

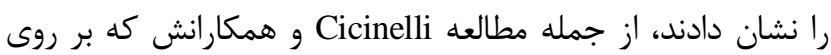

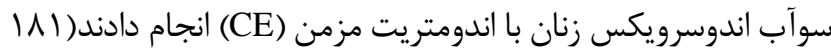

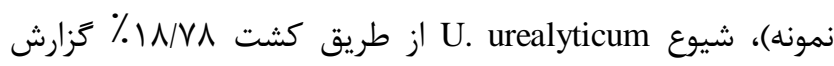

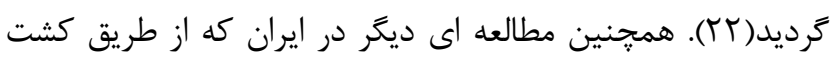

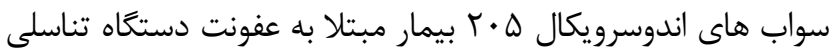
U. توسط نوراميرمظفرى و همكاران انجام گرديد نيز urealyticum به مطالعه هاى مورد مقايسه كه داراى نمونه هاى بيشترى بودندان

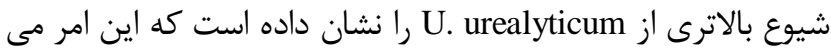

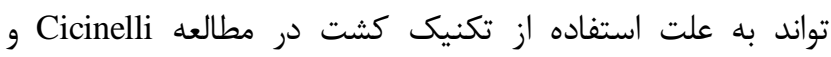
نوراميرمظفرى باشد كه حساسيت و دقت و اختصاصيت آن نسبت تكنيك PCR كه در مطالعه حاضر انجام گرديد، پايين تر است. در يزوهشى كه توسط Saigal و همكارانش بر روى ادرار و سواب مجارى ادرارى مردان و اندوسرويكس زنان كه هردو تروه (191) U. نمونه)، مبتلا به عفونت دستخاه تناسلى بودند انجام شردان

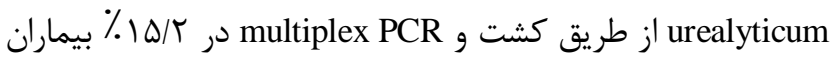

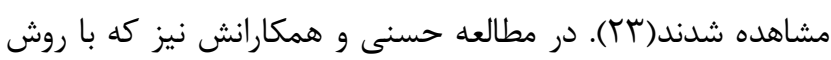

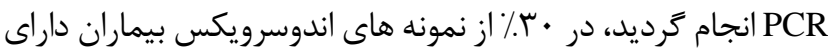




\section{References}

1. Denny E. "I never know from one day to another how I will feel": pain and uncertainty in women with endometriosis. Qual Health Res. 2009; 19(7):985-95. [DOI:10.1177/1049732309338725] [PMID]

2. Khan KN, Fujishita A, Kitajima M, Hiraki K, Nakashima M, Masuzaki H. Intra-uterine microbial colonization and occurrence of endometritis in women with endometriosis. Hum Reprod. 2014; 29(11):244656. [DOI:10.1093/humrep/deu222] [PMID]

3. Naji Omidi F, Abolghasemi J, Chaichian S, Rimaz S, Najmi Z, Mehdizadehkashi A. Evaluation of the factors influencing endometriosis in reproductive age women. MEDICAL SCIENCES. 2016; 26(3) :188-194.

4. Zondervan KT, Becker CM, Koga K, Missmer SA, Taylor RN, Vigano P. Endometriosis. Nat Rev Dis Primers. 2018; 4(1):9. [DOI:10.1038/s41572-0180008-5] [PMID]

5. Khan KN, Fujishita A, Masumoto H, Muto H, Kitajima M, Masuzaki $\mathrm{H}$, et al. Molecular detection of intrauterine microbial colonization in women with endometriosis. Eur J Obstet Gynecol Reprod Biol. 2016; 199:69-75. [DOI:10.1016/j.ejogrb.2016.01.040] [PMID]

6. O'Connell CM, Ferone ME. Chlamydia trachomatis genital infections. Microb Cell. 2016; 3(9):390-403. [DOI:10.15698/mic2016.09.525] [PMID] [PMCID]

7. Ahmadi A, Khodabandehloo M, Ramazanzadeh R, Farhadifar F, Roshani D, Ghaderi E, et al. The relationship between Chlamydia trachomatis genital infection and spontaneous abortion. JRI. 2016; 17(2):110-116.

8. Najar Peerayeh S, Samimi R. Detection of ureaplasma urealyticum in clinical samples from infertile women by polymerase chain reaction. IJPT. 2007; 6(1):23-0.

9. Taylor-Robinson D. Mollicutes in vaginal microbiology: Mycoplasma hominis, Ureaplasma urealyticum, Ureaplasma parvum and Mycoplasma genitalium. Res Microbiol. 2017; 168(9-10):875-81. [DOI:10.1016/j.resmic.2017.02.009] [PMID]

10. Newman L, Rowley J, Vander Hoorn S, Wijesooriya NS, Unemo M, Low N, et al. Global estimates of the prevalence and incidence of four curable sexually transmitted infections in 2012 based on systematic review and global reporting. PloS One. 2015; 10(12):e0143304.

[DOI:10.1371/journal.pone.0143304]

[PMID] [PMCID]

11. Kokkayil P, Dhawan B. Ureaplasma: current perspectives. Indian journal of medical microbiology.
2015; 33(2):205-214. [DOI:10.4103/02550857.154850] [PMID]

12. Waites KB, Xiao L, Paralanov V, Viscardi RM, Glass JI. Molecular methods for the detection of Mycoplasma and ureaplasma infections in humans: a paper from the 2011 William Beaumont Hospital Symposium on molecular pathology. JMD. 2012; 14(5):437-50.

13. Stellrecht KA, Woron AM, Mishrik NG, Venezia RA. Comparison of multiplex PCR assay with culture for detection of genital mycoplasmas. J Clin Microbiol. 2004; 42(4):1528-33. [DOI:10.1128/JCM.42.4.15281533.2004] [PMID] [PMCID]

14. Serin M, Evruke C, Kibar F, KÖKSAL F. Comparison of PCR and cultivation methods to determine the incidence of infections due to mycoplasma hominis and mycoplasma fermentans in women genitourinary tract. Eastern J Med. 2001; 6(2):48-52.

15. Golshani M, Eslami G, Ghobadloo SM, Fallah F, Goudarzi H, Rahbar AS, et al. Detection of Chlamydia trachomatis, Mycoplasma hominis and Ureaplasma urealyticum by multiplex PCR in semen sample of infertile men. Iran J Public Health. 2007; 36(2):50-7.

16. Goshayeshi L, Vahid Roodsari F, Ghazvini K, Namaee $\mathrm{H}$, Amel jamedar S. Pilot study of Chlamydia trachomatis by PCR method in infertile women referring to Mashhad Infertility Research Center. Iran South Med J. 2015; 18(1):92-9. [In Persian]

17. Mirnejad R, Amirmozafari N, Kazemi B. Simultaneous and rapid differential diagnosis of Mycoplasma genitalium and Ureaplasma urealyticum based on a polymerase chain reaction-restriction fragment length polymorphism. Indian J Med Microbiol. 2011; 29(1):33. [DOI:10.4103/0255-0857.76521] [PMID]

18. Hajikhani B, Motallebi T, Norouzi J, Bahador A, Bagheri R, Asgari S, et al. Classical and molecular methods for evaluation of Chlamydia trachomatis infection in women with tubal factor infertility. J Reprod Infertil. 2013; 14(1):29.

19. Amirmozafari N, Jeddi F, Masjedian F, Haghighi L. Prevalence of Mycoplasma hominis and Ureaplasma urealyticum in Genital Tract Infections. RJMS. 2009; 15(60):19-25.

20. Zolfaghari M, Khansarinejad B, Ganji A, Hamzehloo Z, Abtahi H. Frequency Determination of Ureaplasma and Mycoplasma Genitalium Species in Female with Vaginitis Infection using Real-Time PCR. J Arak Uni Med Sci. 2017; 19(116):39-46.

21. Hasani A, Shahrokhi N, Khazar Doust S. Diagnosis of Ureaplasma urealyticum and Mycoplasma hominis bacteria in patients with genital tract infection by PCR. IJIDTM. 1391; 17(58): 50-45. [In Persian] 


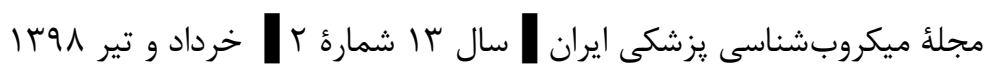

22. Cicinelli E, De Ziegler D, Nicoletti R, Tinelli R, Saliani $\mathrm{N}$, Resta L, et al. Poor reliability of vaginal and endocervical cultures for evaluating microbiology of endometrial cavity in women with chronic endometritis. Gynecol Obstet Investig. 2009; 68(2):108-15. [DOI:10.1159/000223819] [PMID]

23. Saigal K, Dhawan B, Rawre J, Khanna N, Chaudhry R. Genital Mycoplasma and Chlamydia trachomatis infections in patients with genital tract infections attending a tertiary care hospital of North India.IJPM.2016; 59(2):194. [DOI:10.4103/03774929.182019] [PMID]

24. Afrasiabi S, Moniri R, Samimi M, Khorshidi A, Mousavi SGA. The Prevalence of Endocervical Chlamydia trachomatis Infection Among Young Females in Kashan, Iran. JJM. 2015; 8(4):e15576. [DOI:10.5812/jim.8(4)2015.15576]

25. Chamani Tabriz L, Jedi Tehrani M, Mousavi Jarahi A, Zeraati H, Ghasemi J, Asgari S, et al. Molecular evaluation of the frequency of Chlamydia trachomatis infection in women referred to Tehran obstetrics and gynecology clinics. JRI. 2006; 7(3):242-234. 